\title{
Pterocarpus marsupium Derived Phyto-Synthesis of Copper Oxide Nanoparticles and their Antimicrobial Activities
}

\author{
Rajgovind1, Gaurav Sharma', Deepak Gupta $\mathrm{Kr}^{3}$, Nakuleshwar Dut Jasuja ${ }^{1 *}$ and Suresh Joshi $\mathbf{C}^{2}$ \\ ${ }^{1}$ School of Sciences, Suresh Gyan Vihar University, Rajasthan, India \\ ${ }^{2}$ Department of Zoology, University of Rajasthan, Jaipur, India \\ ${ }^{3}$ Centre for Converging Technologies, University of Rajasthan, Jaipur, India
}

\begin{abstract}
In present study, copper oxide nanoparticles (CuONPs) synthesized by quick and eco-friendly phytogenicreduction of copper salt (copper sulphate $\mathrm{CuSO}_{4} \cdot \mathrm{H}_{2} \mathrm{O}$ ) solution with Pterocarpus marsupium extract. UV-VIS spectrometry indicated formation of nanoparticles via absorption spectra of copper colloidal solution at $442 \mathrm{~nm}$. Phytosynthesis of CuONPs were further characterized by Transmission electron microscopy; scanning electron microscopy and Fourier transform infrared spectroscopy. The experimental results showed that diameter of CuONPs in colloidal solution were $<40 \mathrm{~nm}$. Further, antibacterial activities of CuONPs were determined against Gram negative Escherichia coli- MTCC-9721, Proteus vulgaris- MTCC-7299, Klebsiella pneumonia- MTCC-9751 and Gram positive i.e. Staphylococcus aureus- MTCC-9442, Staphylococcus. epidermidis- MTCC- 2639, Bacillus cereus- MTCC-9017 bacteria by well agar diffusion and microdilution method. Notably, The CuONPs showed an effective antibacterial activity against all test microorganisms where K. pneumonia and E.coli showed maximum ZOI and MIC respectively i.e. $24 \mathrm{~mm}$ and $6 \mu \mathrm{g} / \mathrm{ml}$.
\end{abstract}

Keywords: Phyto-reduction; Copper oxide nanoparticles; Pterocarpus marsupium; Antibacterial activity; SEM; TEM

\section{Introduction}

Conventionally, copper and its complexes have been used as water purifiers, algaecide, fungicides, and as antibacterial and antifouling agents $[1,2]$. In last decade metal is being tried set to minimal size of particles as nanoparticles due to idiosyncratic properties. CuONPs exhibited huge potential as catalysis, optics, electronics, batteries, gas sensors, solar energy conversion tools, high temperature superconductors [3-7] and found very persuasive in past studies, evaluating antibacterial activity and roles in other ailment $[8,9]$. Notably, CuONPs explored their potential in antimicrobial activities against many infectious organisms such as Vibrio cholera, Syphillis typhus, Staphylococcus aureus, E. coli, Pseudomonas aeruginosa and Bacillus subtilis. [10-12]. These particles showed great possibilities in malignant condition as mediator in chemotherapeutic doses delivery and targeting tumor cell. Synthesis of metallic nanoparticles is carried out by several physical and chemical methods that include laser ablation [13], ion sputtering [14], solvo thermal synthesis [15], chemical reduction [16], and sol-gel [17,18] method, involve toxic solvents, high temperature, energy and high pressure conversion. Few studies held, were focused on Microbe mediated synthesis as of not practical for industries due to laboratory maintenance. The growing need of environmental supporting phenomenon for synthesis nanoparticles, phytogenic reduction methods (phytosynthesis) are more acceptable, easy, efficient, and eco-friendly. Pterocarpus marsupium belongs family Fabales, also known as Vijayasar or the Indian Kino Tree, is a medium to large, deciduous tree that can grow up to 30 meters tall. It is native to India, Nepal, and Sri Lanka. Notably, parts of the Indian Kino (heartwood, leaves and flowers) have long been used for their medicinal properties in Ayurveda.

Reportedly, Deepa et al. assessed antimicrobial activity of ethanolic extract of Pterocarpus marsupium Roxb Bark [19].

In present study Pterocarpus marsupium plant extract is used as reducing and capping agent [20] and synthesized CuONPs were further, characterized by UV-visible spectroscopy, TEM, SEM and FTIR followed by anti-bacterial activities. Umesh et al. reported green synthesis of silver nanoparticles using Artocarpus heterophyllus Lam. seed extract [21]. Das et al. described green synthesis of silver nanoparticles using Sesbania grandiflora leaf extract [22]. Abuelmagd et al. studied green synthesis of gold nanoparticles using Punica granatum L. extract [23]. Some of plant materials such as Aegle marmelos leaf extract [24] and Syzygium aromaticum aqueous extract [25] have been used for the synthesis of CuONPs.

\section{Materials and Methods}

\section{Materials}

Pterocarpus marsupium (Fabales) a deciduous tree, belonging to the group called rasayana in ayurvedic system of medicine. Rasayana drugs are immunomodulators and relieve stress of the body. In ayurveda, aqueous extract of heart-wood of $P$. marsupium is used in treatment of diabetes. Although there are several reports on P. marsupium as an anti-diabetic drug.

The heart-wood of P. marsupium were collected and identified from Department of Botany, University of Rajasthan, Jaipur. Further, wood were thoroughly washed, dried and finally powdered to store in airtight container at cool and dry place for next preparation as phytogenic reduction of copper sulphate salt.

*Corresponding author: Nakuleshwar Dut Jasuja, School of Sciences, Suresh Gyan Vihar University, Jaipur, Rajasthan, India, Tel: +91-9414658277; E-mail: nakuljasuja@gmail.com

Received April 03, 2015; Accepted April 22, 2015; Published April 29, 2015

Citation: Rajgovind, Sharma G, Deepak Gupta Kr, Jasuja ND, Suresh Josh C (2015) Pterocarpus marsupium Derived Phyto-Synthesis of Copper Oxide Nanoparticles and their Antimicrobial Activities. J Microb Biochem Technol 7: 140 144. doi:10.4172/1948-5948.1000195

Copyright: $\odot 2015$ Rajgovind, et al. This is an open-access article distributed under the terms of the Creative Commons Attribution License, which permits unrestricted use, distribution, and reproduction in any medium, provided the original author and source are credited 
Citation: Rajgovind, Sharma G, Deepak Gupta Kr, Jasuja ND, Suresh Joshi C (2015) Pterocarpus marsupium Derived Phyto-Synthesis of Copper Oxide Nanoparticles and their Antimicrobial Activities. J Microb Biochem Technol 7: 140-144. doi:10.4172/1948-5948.1000195

\section{Synthesis of copper oxide nanoparticles}

The broth of $P$. marsupium wood was prepared by boiling $5 \mathrm{gm}$ plant material (heart-wood) with $100 \mathrm{ml}$ of distilled water for $15 \mathrm{~min}$ before final decantation. The broth was filtered through pal funnel using Whatman filter paper no 1 and stored at $-18^{\circ} \mathrm{C}$. Next, as filtrate was introduced in $1 \mathrm{mM} \mathrm{CuSO} \cdot \mathrm{H}_{2} \mathrm{O}$ aqueous solution at $50^{\circ} \mathrm{C}$ on temperature controlled magnetic stirrer, a greenish solution was formed, indicating the formation of copper oxide nanoparticles. The resultant solution was centrifuged at $15000 \mathrm{rpm}$ for $15 \mathrm{~min}$, followed by several time washing of finally collected pellet. Sequentially, the pellet was vacuum dried and stored for further use.

\section{Characterization of the synthesized copper oxide nanoparticles}

The optical absorbance of CuONPs solution was recorded on UVvisible spectroscopy 1800 of Shimadzu, Kyoto, Japan. The fractional amount of CuONPs powder was coated with a thin layer of gold by sputter coating and examined in a scanning electron microscope, carl zeiss EVO-18, 30KV. FTIR spectra were recorded on IR-Affinity 1, Shimadzu Fourier transform infrared spectrometer at room temperature by implanting $<0.01 \mathrm{~g}$ of copper nanopowder with $\mathrm{KBr}$ salt. Further high resultant images were obtained by HRTEM using Techni G2, S-twin 200KV.

\section{Determination of anti-bacterial activities of $\mathrm{CuO}$ nanoparticles}

The CuONPs and aqueous extract prepared by $P$. marsupium were used to evaluate antimicrobial activity against Gram (-) and Gram (+) Bacteria (E. coli- MTCC-9721, P. vulgaris- MTCC-7299, K. pneumoniaMTCC-9751, S. aureus- MTCC-9442, S. epidermidis- MTCC- 2639 and B. cereus- MTCC-9017 ) on MHA plates by agar well diffusion method $[26,27]$. Bacterial strain were kept up on nutrient agar slants that included peptone $(5.0 \mathrm{~g})$, meat extract $(1.0 \mathrm{~g})$, yeast extract $(2.0$ $\mathrm{g})$, sodium chloride $(5.0 \mathrm{~g})$, and agar $(15.0 \mathrm{~g})$ per liter of distilled water.

The Minimum Inhibitory Concentration (MIC) method for all test bacterial strains were also determined [28,29]. MIC of the CuONPs and Gentamicin performed by the broth micro dilution method. The $50 \mu \mathrm{L}$ of nutrient broth were added in 96 -well plate followed by $50 \mu \mathrm{L}$ of stock solution of CuONPs by Two-fold serial dilutions method producing $100 \mu \mathrm{g} / \mathrm{mL}$ to $0.78 \mu \mathrm{g} / \mathrm{mL}$ concentration. The each will inoculated with $5 \mu \mathrm{L}$ bacterial culture incubated overnight at $37^{\circ} \mathrm{C}$ in nutrient broth and adjusted to a final density of $10 \mathrm{CFU} / \mathrm{mL}$ by $0.5 \mathrm{McF}$ arland standards. Briefly, different concentrations of Gentamicin and CuONPs prepared by using regular ascending interval i.e. $1 \mu \mathrm{g} / \mathrm{mL}$ to $55 \mu \mathrm{g} / \mathrm{mL}$ were used for MIC. Sterilized nutrient broth was used as the (-) control and inoculated broth was used as the $(+)$ control. After incubation for 24 hours at $37^{\circ} \mathrm{C}$, MIC were determined with an ELISA reader (Infinite 200 ) as the lowest concentration of compound whose absorbency was comparable with the negative control wells. Results are expressed as the mean values of three independent determinations.

\section{Statistical Analysis}

The grouped data were statistically evaluated using ANOVA with SPSS16 software. Values are presented as the mean \pm SD of the three replicates of each experiment.

\section{Results and Discussion}

The copper sulphate solution and fresh broth of P. marsupium were sky-blue and Yellowish-brown respectively. The addition of $P$. marsupium extracts to copper sulphate solution turned the solution to green color at $50^{\circ} \mathrm{C}$ confirmed formation of CuONPs (Figure 1).

\section{UV-visible spectroscopy}

Synthesis of CuONPs using extract of heart-wood of $P$. marsupium observed by UV-visible spectroscopy. Reduction of copper sulphate solution to CuoNPs was confirmed by measuring the UV-Vis spectrum at the range of $200-800 \mathrm{~nm}$. The UV-Vis absorption spectrum of sample is recorded and shown in Figure 2. As expected, $\mathrm{CuO}$ nanoparticles show an absorption peak between 400 and $500 \mathrm{~nm}$ i.e. $442 \mathrm{~nm}$ that can be contributed to the characteristic absorption of CuONPs.

\section{Scanning Electron Microscope (SEM) and Transmission Electron Microscopy (TEM)}

SEM is source for information about the size and morphology details of the CuONPs. As understanding the image of CuONPs, The fractional amount of CuONPs powder was coated with a thin layer of gold by sputter coating and examined in a scanning electron microscope. Figure $3 b$ shows the scanning electron micrograph of the copper oxide nanoparticles obtained from the phytogenic-reduction method.

TEM proficiency was used to project the sound structure of the CuONPs (Figure 3a). TEM grids were fitted out by addition of $5 \mu \mathrm{L}$ of the CuONPs solution on carbon-coated copper grids and drying under
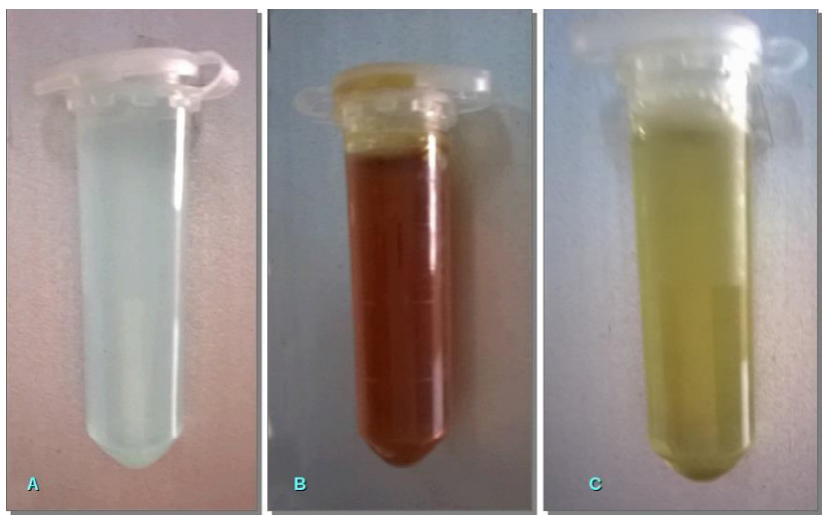

Figure 1: A visual image of (a) copper sulphate solution (b) broth of $P$. marsupium and (c) CuONPs colloid.

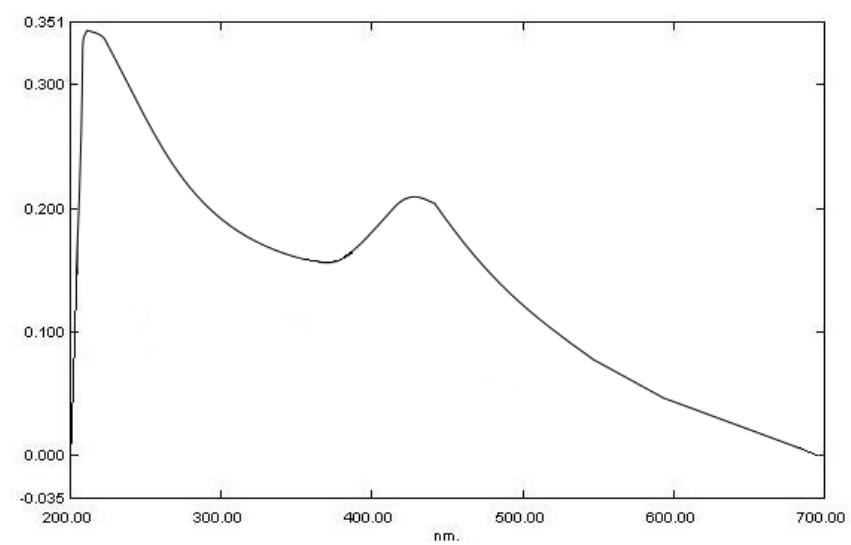

Figure 2: UV-Vis spectrum of CuO nanoparticles phyto-synthesized by $P$. marsupium. 
Citation: Rajgovind, Sharma G, Deepak Gupta Kr, Jasuja ND, Suresh Joshi C (2015) Pterocarpus marsupium Derived Phyto-Synthesis of Copper Oxide Nanoparticles and their Antimicrobial Activities. J Microb Biochem Technol 7: 140-144. doi:10.4172/1948-5948.1000195

UV lamp. The experimental results showed that the shape of prepared $\mathrm{CuONPs}$ was spherical with diameters that ranged from $20 \mathrm{~nm}$ to 50 $\mathrm{nm}$ (Figure 3a) and found in form of nanocluster. The larger copper particles may be due to the aggregation of the smaller ones, during the TEM analysis. Facsimile etiology was accessed when employing $\mathrm{Cu}\left(\mathrm{NO}_{3}\right) 2.3 \mathrm{H}_{2} \mathrm{O}$ as demonstrated by Anandan et al. [30].

\section{Fourier transform infrared spectroscopy (FTIR)}

CuONPs solution was centrifuged at $15,000 \mathrm{rpm}$ for 20 minute and obtained solid residue subjected to several time washing with distilled water followed by drying for next 24 hours. The dusty amount of powder were used for FTIR analysis, which were performed on a IRAffinity-1-Shimadzu. The FTIR peaks were identified and expressed in wave numbers $\left(\mathrm{cm}^{-1}\right)$.
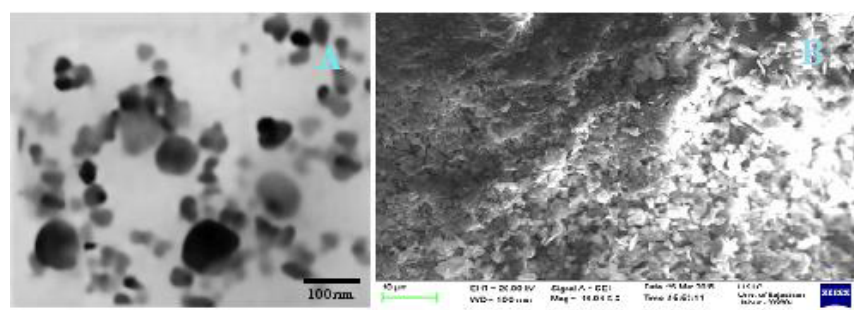

Figure 3: (a) Bright field TEM image of CuONPs.(b) A typical of SEM image of phyto-reduced copper nanoparticles.
The refined CuONPs possessed absorption peaks at 1149, 1616, 1645 , and $3333 \mathrm{~cm}^{-1}$ due to cyclic $\mathrm{C}-\mathrm{O}-\mathrm{C}, \mathrm{C}=\mathrm{O}$ and $\mathrm{OH}$ functional groups, respectively (Figure 4). It may be inferred that the bioactive ingredients of $P$. marsupium was the presumptive reducing agent which was concerned in the Phyto-synthesis of CuONPs and might have organized a layer on the CuONPs (i.e., Phyto-capping) that may have hindered the agglomeration of the Nano-sized particles would have stabilized them.

\section{Determination of anti-bacterial activities of $\mathrm{CuO}$ nanoparticles}

Six bacterial strains were used for antimicrobial activity where three Gram (-) bacteria E. coli- MTCC-9721, P. vulgaris- MTCC-7299, K. pneumonia- MTCC-9751 and three Gram (+) bacteria S. aureusMTCC-9442, S. epidermidis- MTCC- 2639, B. cereus- MTCC-9017. Bacterial response to CuONps and antibiotics is evaluated using well diffusion assay. Prepared CuONPs suspension was added into the wells. The prepared samples were incubated for 15 minute at $4^{\circ} \mathrm{C}$ followed by $37^{\circ} \mathrm{C}$ for $24 \mathrm{~h}$. Zone of inhibition (ZOI) were measured on scale in $\mathrm{mm}$ around the well after the incubation period. The mean values of each triplicate were reported.

The outcomes pointed that CuONPs have bear down dosedependent state against both gram negative and gram positive microorganisms. All these bacteria were found susceptible against the CuONPs as growth of these microbes reduced with the increase in concentration of CuONPs (Figure 5).

ФSHIMADZU

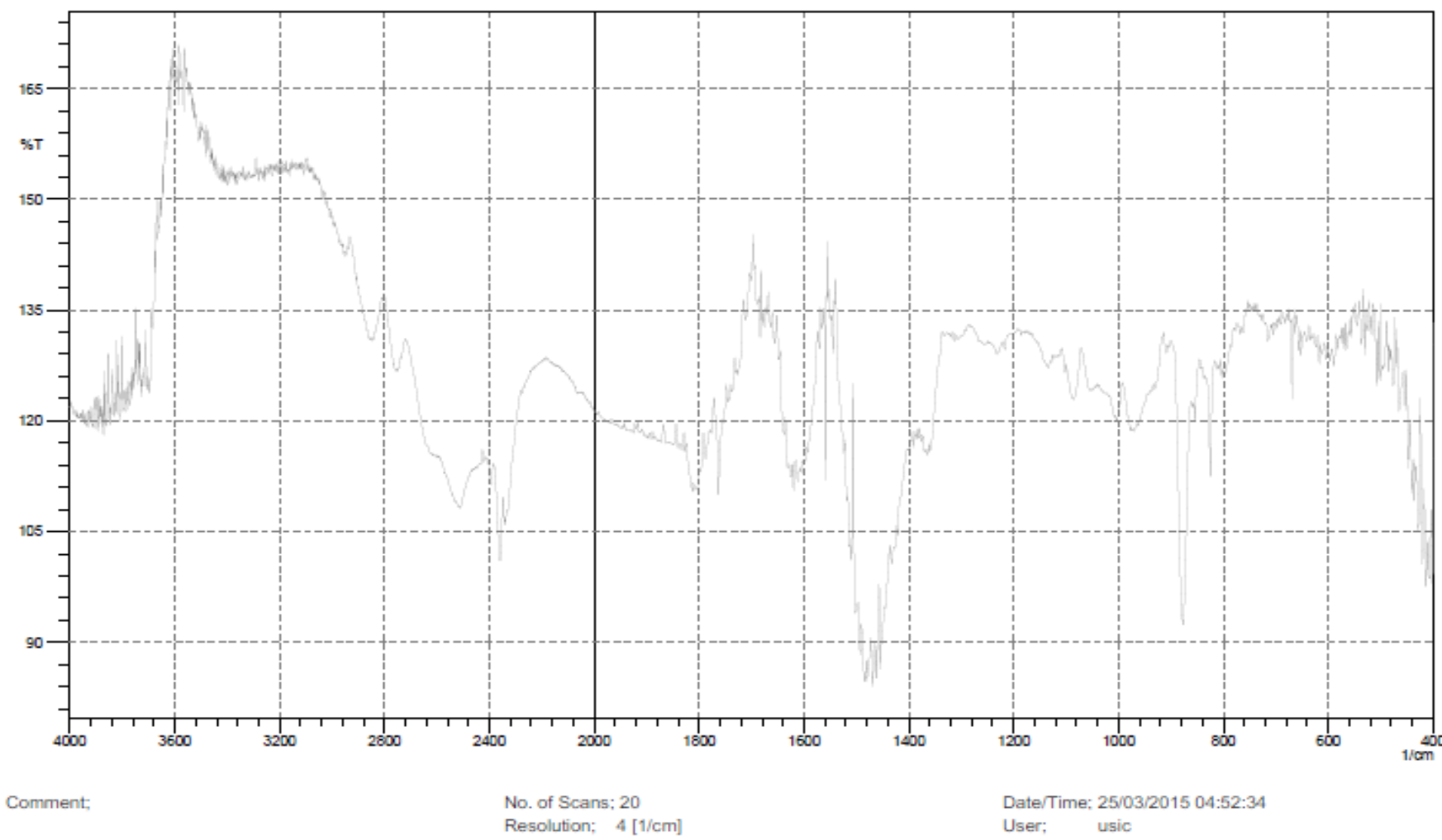

Figure 4: FTIR spectrum of $P$. marsupium capped CuONPs. 
Citation: Rajgovind, Sharma G, Deepak Gupta Kr, Jasuja ND, Suresh Joshi C (2015) Pterocarpus marsupium Derived Phyto-Synthesis of Copper Oxide Nanoparticles and their Antimicrobial Activities. J Microb Biochem Technol 7: 140-144. doi:10.4172/1948-5948.1000195

The effectiveness of CuONPs against all six microbes compared with the control, the diameters of ZOI $(\mathrm{mm})$ vary for all the test bacteria at contrastive level of CuONPs concentration. It was revealed that $0.08 \mathrm{mmol} / \mathrm{mL}$ colloid solution of CuONPs displayed $25 \mathrm{~mm}$ clear inhibitory zone against $K$. pneumonia after incubation for $24 \mathrm{~h}$ followed by E. coli $(24 \mathrm{~mm})$, then $23 \mathrm{~mm}$ for B. cereus and $22 \mathrm{~mm}$ for P. vulgaris, minimum for $S$. epidermidis and $S$. aureus $(20 \mathrm{~mm})$ proposing that phytosynthesized $\mathrm{CuONPs}$ have valuable antibacterial effect against Gram (-) than Gram (+) Bacteria (Table 1).

The upshot of the present study are compatible with other findings that point greater action of CuONPs against Gram (-) bacteria [31]. Notably, results signal that the CuONPs are more active against $K$. pneumoniae a Gram (-) bacteria that is may be due to the expedited influx of Nano-sized CuONPs into the cell wall of Gram (-) microorganism which made-up of a specific outer membrane with a one-on-one layer of peptidoglycan alike to cell wall of Gram $(+)$ microorganism with many layer of peptidoglycan $[32,33]$. The idiosyncratic high surface/volume
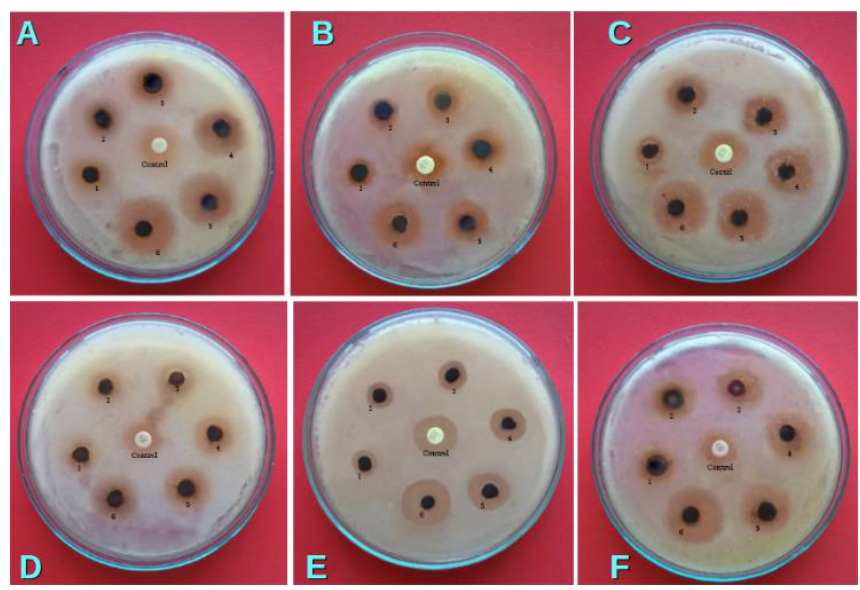

Figure 5: A visual image of antibacterial activity of CuONPs against (a) $K$ pneumoniae, (b) S. epidermidis, (c) B. cereus, (d) S. aureus, (e) P. vulgaris and (f) E. coli. ratios of CuONPs ease to interact with the cell membrane bacteria [34] Which prompt the necrosis of the microorganism cell [35].

Minimum inhibitory concentration of CuONPs (Table 2) was assessed against all test bacteria. The copper nanoparticles exposed muffled MIC against E. coli and K. pneumoniae at $6 \mu \mathrm{g} / \mathrm{mL}$ autem blaring MIC was found against $S$. aureus i.e. $28 \mu \mathrm{g} / \mathrm{mL}$. Effectiveness of CuONPs against both Gram negative and Gram positive bacteria proposing as broad spectrum potential of nanoparticle. Bacterial colony stamp down by cell filaments formation influenced by $\mathrm{CuONPs}$ subjected to bacterial cell membrane destruction [36] and CuONPs may encounter multiple toxic effects such as genesis of free radicals assaulting membrane lipids and sequential free-radical induced impairment of membranes [3739], formation of irregularly shaped pits in outer bacterial membrane and changes in permeability were linked up with metal exhaustion and liberal spillage of membrane proteins and lipopolysaccharides [40], Metallic nanoparticles undergoes slow oxidation with vent of their ions which lead to lose of replicative ability by DNA [41,42] and to the inhibition of expression of ribosomal subunits and to the inactivation of some cellular proteins and enzymes, essential to ATP production

\section{Conclusion}

In this study CuONPs were prepared using extracts of $P$. marsupium, a plant abundantly found throughout in India, as reducing agent. The outcomes were very gleaming since the extract supports the fabrication of CuONPs at $50^{\circ} \mathrm{C}$ with an accelerated kinetics, without noxious chemicals. The method was easy to execute in one-on-one step. The copper nanoparticles synthesized by this method were bear-down nominees for its use in biological instrumentation and antibacterial activity. The diameter of the copper nanoparticles is $<40$ $\mathrm{nm}$, as shown by TEM analysis. Surely, the CuONPs produced by this method, initiative to a new itinerary to study conductive activity and antimicrobial properties.

\section{References}

1. Lee S, Choi SUS, Li S, Eastman JA (1999)Measuring thermal conductivity of fluids containing oxide nanoparticles. J Heat Transfer 121: 280-289.

2. Rakhshni AE (1986) Preparation, characteristics and photovoltaic properties of cuprous oxide-a review. Solid State Electron 29: 7-17.

\begin{tabular}{|c|c|c|c|c|c|c|}
\hline \multirow{2}{*}{$\begin{array}{c}\text { copper nanoparticle } \\
\text { Concentration (mmol/ } \\
\mathrm{mL})\end{array}$} & \multicolumn{6}{|c|}{ Bacterial Sp (zone of inhibition-mm) } \\
\hline & K. pneumoniae $(\mathrm{A})$ & S. epidermidis (B) & B. cereus $(\mathrm{C})$ & S. aureus (D) & P. vulgaris $(\mathrm{E})$ & $E$ coli $(\mathrm{F})$ \\
\hline .0025 & 12 & 11 & 10 & 11 & 12 & 10 \\
\hline .005 & 13 & 12 & 13 & 13 & 15 & 11 \\
\hline .01 & 15 & 14 & 15 & 14 & 16 & 14 \\
\hline .02 & 18 & 16 & 17 & 16 & 17 & 17 \\
\hline .04 & 21 & 17 & 20 & 18 & 18 & 19 \\
\hline .08 & 25 & 20 & 23 & 20 & 22 & 24 \\
\hline control & 13 & 12 & 14 & 13 & 14 & 12 \\
\hline
\end{tabular}

Table 1: Antibacterial activity (ZOI in $\mathrm{mm}$ ) of CuONPs against test bacterial strains.

\begin{tabular}{|c|c|c|}
\hline \multirow{2}{*}{ Bacterial Sp } & \multicolumn{2}{|c|}{$\mathrm{MIC}(\mu \mathrm{g} / \mathrm{mL})$} \\
\cline { 2 - 3 } & CuONPs & \\
\hline K. pneumoniae (A) & $6 \mu \mathrm{g} / \mathrm{mL}$ & $6 \mu \mathrm{g} / \mathrm{mL}$ \\
\hline S. epidermidis (B) & $21 \mu \mathrm{g} / \mathrm{mL}$ & $15 \mu \mathrm{g} / \mathrm{mL}$ \\
\hline B. cereus (C) & $10 \mu \mathrm{g} / \mathrm{mL}$ & $6 \mu \mathrm{g} / \mathrm{mL}$ \\
\hline S. aureus (D) & $28 \mu \mathrm{g} / \mathrm{mL}$ & $15 \mu \mathrm{g} / \mathrm{mL}$ \\
\hline P. vulgaris (E) & $15 \mu \mathrm{g} / \mathrm{mL}$ & $10 \mu \mathrm{gg} / \mathrm{mL}$ \\
\hline E Coli (F) & $6 \mu \mathrm{gg} / \mathrm{mL}$ & $6 \mu \mathrm{g} / \mathrm{mL}$ \\
\hline
\end{tabular}

Table 2: Minimal Inhibitory Concentration (MIC), in $\mu \mathrm{g} / \mathrm{ml}$, of CuONPs against test bacteria. 
Citation: Rajgovind, Sharma G, Deepak Gupta Kr, Jasuja ND, Suresh Joshi C (2015) Pterocarpus marsupium Derived Phyto-Synthesis of Copper Oxide Nanoparticles and their Antimicrobial Activities. J Microb Biochem Technol 7: 140-144. doi:10.4172/1948-5948.1000195

3. Premkumar T, Geckeler KE (2006) Nanosized CuO particles via a supramolecular strategy. Small 2: 616-620

4. Ren G, Hu D, Cheng EW, Vargas-Reus MA, Reip P, et al. (2009) Characterisation of copper oxide nanoparticles for antimicrobial applications. Int J Antimicrob Agents 33: $587-590$

5. Hsieh CT, Chen JM, Lin HH, Shih HC (2003) Synthesis of well-ordered CuO nanofibers by a self-catalytic growth mechanism. Appl Phys Lett 82: 33163318

6. Zhang X, Wang G, Liu X (2008) Different CuO nanostructures: synthesis, characterization, and applications for glucose sensors. J Phys Chem C Nanomater Interfaces 112: 16845-16849.

7. Turner T (1908) Transparent Silver and Other Metallic Films. Proc. Roy. Soc. Lond. A 81: 301-310.

8. Gaurav S, Nakuleshwar DJ, Mohammad IA, Suresh CJ (2014) A Review on Nanomedicinal and Nanosensing Potential of Nanoparticles. Int. J. Biol. Chem 8: $58-84$

9. Anisa M, Abdallah SD, Singer PA (2003) 'Mind the gap': science and ethics in nanotechnology. Nanotechnology 14: 282-283.

10. Akhavan O, Ghaderi E (2012) Cu and CuO nanoparticles immobilized by silica thin films as antibacterial materials and photocatalysts. Surface and Coatings Technology 205: 219-223.

11. Hassan MS, Amna T, Yang OB, E1-Newehy MH, Al-Deyab SS, et al, (2012) Smart copper oxide nanocrystals: synthesis, characterization, electrochemical and potent antibacterial activity. Colloids Surf B: Biointer-faces 97: 201-206.

12. Stoimenov PK, Klinger RL, Marchin RL, Klabunde KJ (2002) Metal oxide nanoparticles as bactericidal agents. Langmuir 18: 6679-6686.

13. Mafune F, Kohno JY, Takeda Y, Kondow T, Sawabe H (2001) Formation of gold nanoparticles by laser ablation in aqueous solution of surfactant. Journal of Physical Chemistry B 105: 5114-5120.

14. Raffi M, Rumaiz AK, Hasan MM Shah SI (2007) Studies of the growth parameters for silver nanoparticle synthesis by inert gas condensation. J. Mater. Res 22: 3378-3384.

15. Rosemary MJ, Pradeep T (2003) Solvothermal synthesis of silver nanoparticles from thiolates. J Colloid Interface Sci 268: 81-84.

16. Chaki NK, Sundrik SG, Sonawane HR, Vijayamohanan K (2002) Single phase preparation of monodispersed silver nanoclusters using a unique electron transfer and cluster stabilising agent, triethylamine. J. Chem. Soc. Chem. Commun. 76: 76-7.

17. Madzlan A (2013) Size-controlled synthesis of $\mathrm{SnO} 2$ nanoparticles by sol-ge method. Materials Letters 91: 31-34.

18. Reda SM (2010) Synthesis of $\mathrm{ZnO}$ and Fe2O3 nanoparticles by sol-gel method and their application in dye-sensitized solar cells. Mater. Sci. Semicond. Process 13: 417-425.

19. Deepa R, Manjunatha H, Krishna V, Kumara Swamy BE (2014) Evaluation of Antimicrobial Activity and Antioxidant Activity by Electrochemical Method of Ethanolic Extract of Pterocarpus marsupium Roxb Bark. J Biotechnol Biomater 4: 166-169.

20. Das SK, Marsili E (2010) A Green Chemical Approach for the Synthesis of Goldn Nanoparticles: Characterization and Mechanistic Aspect. Rev. Environ. Sci. Bio/Technol 9: 199-204.

21. Umesh BJ, Vishwas AB (2013) Green synthesis of silver nanoparticles using Artocarpus heterophyllus Lam. seed extract and its antibacterial activity. Industrial Crops and Products 46: 132-137.

22. Das J, Paul DM, Velusamy P (2013) Sesbania grandiflora leaf extract mediated green synthesis of antibacterial silver nanoparticles against selected human pathogens. A Mol Biomol Spectrosc 104: 265-270.

23. Abuelmagd M. Abdelmonema, Rehab M, Aminb (2014) Rapid Green Synthesis of Metal Nanoparticles using Pomegranate Polyphenols. IJSBAR 15: 57-65

24. Angajala G, Pavana P, Subashini R (2014) One-step biofabrication of coppe nanoparticles from Aegle marmelos correa aqueous leaf extract and evaluation of its anti-inflammatory and mosquito larvicidal efficacy. RSC Adv 4: 5145951470.

25. Subhankari I, Nayak PL (2013) Synthesis of copper nanoparticles using syzygium aromaticum (cloves) aqueous extract by using green chemistry World J. Nano Sci. Technol 2: 14-17,

26. Provine H, Hadley S (2000) Preliminary evaluation of a semisolid aga antifungal susceptibility test for yeasts and molds. J Clin Microbiol 38: 537-541.

27. Gaurav S, Manoj K, Mohammad IA, Nakuleshwar DJ (2014) Effect of Carbon Content, Salinity and $\mathrm{pH}$ on Spirulina platensis for Phycocyanin Allophycocyanin and Phycoerythrin Accumulation. J Microb Biochem Techno 6: 202-206.

28. Wiegand I, Hilpert K, Hancock RE (2008) Agar and broth dilution methods to determine the minimal inhibitory concentration (MIC) of antimicrobial substances. Nat Protoc 3: 163-175

29. Gaurav S, Nakuleshwar DJ, Rajgovind, Prerna S, Suresh CJ (2014) Synthesis Characterization and Antimicrobial Activity of Abelia grandiflora Assisted AgNPs. J Microb Biochem Technol 6: 274-273.

30. Anandan S, Yang S (2007) Emergent Methods to Synthesize and Characterize Semiconductor $\mathrm{CuO}$ nano particles with various morphologies - an overview J Exp Nanosci. 2: 23-56

31. Longano D, Ditaranto N, Sabbatini L, Torsi L, Cioffi N (2012) Synthesis and antimicrobial activity of copper nanomaterials. Nano-Antimicrobials: Progress and Prospects 3: 85-117.

32. Hajipour MJ, Fromm KM, Ashkarran AA, Jimenez de Aberasturi D, de Larramendi IR, et al. (2012) Antibacterial properties of nanoparticles. Trends Biotechnol 30: 499-511.

33. Silhavy TJ, Kahne D, Walker S (2010) The bacterial cell envelope. Cold Spring Harb Perspect Biol 2: a000414.

34. Chatterjee AK, Sarkar RK, Chattopadhyay AP, Aich P, Chakraborty R, et al. (2012) A simple robust method for synthesis of metallic copper nanoparticles of high antibacterial potency against E. coli. Nanotechnology 23: 085103.

35. Theivasanthi T, Alagar M (2011) Studies of copper nanoparticles effects on microorganisms. Ann Bio Res 2: 368-373.

36. Chatterjee AK, Chakraborty R, Basu T (2014) Mechanism of antibacterial activity of copper nanoparticles. Nanotechnology 25: 135101.

37. Danilczuk M, Lund A, Sadlo J, Yamada H, Michalik J (2006) Conduction electron spin resonance of small silver particles. Spectrochim Acta A Mo Biomol Spectrosc 63: 189-191.

38. Lok CN, Ho CM, Chen R, He QY, Yu WY, et al. (2007) Silver nanoparticles: partial oxidation and antibacterial activities. J Biol Inorg Chem 12: 527-534.

39. Banerjee M, Mallick S, Paul A, Chattopadhyay A, Ghosh SS (2010) Heightened reactive oxygen species generation in the antimicrobial activity of a three component iodinated chitosan-silver nanoparticle composite. Langmuir 26 : 5901-5908.

40. Sondi I, Salopek-Sondi B (2004) Silver nanoparticles as antimicrobial agent: a case study on E. coli as a model for Gram-negative bacteria. J Colloid Interface Sci 275: 177-182.

41. Feng QL, Wu J, Chen GQ, Cui FZ, Kim TN, et al. (2000) A mechanistic study of the antibacterial effect of silver ions on Escherichia coli and Staphylococcus aureus. J Biomed Mater Res 52: 662-668.

42. Yamanaka MK, Hara, Kudo J (2005) Bactericidal actions of a silver ion solution on Escherichia coli, studied by energy-filtering transmission electron microscopy and proteomic analysis. Applied and Environmental Microbiology 71: 7589-7593. 